\title{
The Application of Multimodal Discourse Analysis Theory in the College English Teaching
}

\author{
WANG Bing \\ Leshan Normal University, Leshan, China
}

\begin{abstract}
Nowadays, the multimodal discourse analysis theory becomes increasingly important in the language teaching. This paper tries to elaborate the ways to apply the multimodal discourse analysis theory into College English teaching after analyzing the status-quo of College English teaching on the basis of the theory and the significance of the application of multimodal discourse analysis theory in the College English teaching, hoping to contribute to the College English teaching reform.
\end{abstract}

Keywords: application, multimodal discourse theory, College English

\section{Introduction}

In the language teaching, one of the important standards to measure the teaching effect is the sufficient and effective communication between the teachers and students in order to achieve the communicative purpose. With the development of the computer science and the improvement of the cognitive level for people, the language is no longer regarded as the only way of expression. Pictures, audios, and videos begin to play as an increasingly important role both in expressing the meanings and conveying the information as the language. The multimodal discourse analysis theory is an inspiration to the language teaching. The College English class is no longer confined to one mode-the language, but expanded to many modes, including pictures, PPTs, music, and Internet, etc. The application of multimodal discourse analysis theory in the College English teaching can play a positive part in pushing College English teaching reform, enhancing the teaching efficiency.

\section{The Multimodal Discourse Theory and Multimodal Teaching}

The multimodal discourse analysis is a brand-new form of discourse analysis based on Halliday's social semiotic theory, including language, pictures, space, and other textual resources. This raises the discourse analysis from the social symbols to multimodal texts, such as the images, audios, and motions, etc. In 1977, Barthes's Rhetoric of the Image is the starting point of the multimodal discourse analysis. In 1994 and 1996 O’Toole and Kress and Van Leeuwen publish the Language of Displayed Art and Reading Images, which mark the preliminary achievements in the multimodal discourse analysis. After then multimodal discourse analysis develops greatly in the theory and practice, Kress makes a deeper study of the multimodal teaching (Kress \& Van Leeuwen, 1996).

WANG Bing, Master, associate professor, Foreign Language School, Leshan Normal University, Leshan, China. 
The multimodal teaching refers to the process of constructing the meaning through a variety of symbols, such as oral language, written language, body language, pictures, colors, music, videos, motions, which are interrelated and inter-dependent. As for English teaching, the application of multimode can be regarded as the interaction among many symbolic resources such as language, audios, pictures, and motions, etc., through the usage of the sense of hearing, vision, and touch, etc., which reforms the traditional teaching mode and improves the teacher's teaching ability, thus creating the efficient English class.

\section{The Status-Quo of the Application of Multimodal Discourse in the College English Teaching}

Although the foreign language learning focuses on the language itself, the teaching centered just on the language can't help improve the student's mastery of the language fundamentally. In the College English teaching, because of its limited class time for teaching and the specialty of the language, teachers dominate the class time up to $60 \%-80 \%$. In the traditional classroom teaching, teachers just use the blackboard, oral statements, and some assisting body language to help the teaching, which leads to students' loss of interest in English learning because of its boredness. Students have trouble concentrating on the study.

As a new kind of teaching, the multimodal teaching breaks the mold of traditional teaching. It takes advantage of the Internet resources, pictures, and videos, etc., to involve the students in the language learning. The teacher chooses different modes according to the teaching content, using modern teaching media. For example, when the teacher explains the new words, the context can help the students identify the meanings better or the video clips containing the new words can consolidate the memory. In this way the teaching quality and efficiency will be enhanced.

\section{The Significance of the Application of Multimodal Discourse Analysis Theory Into the College English Teaching}

The multimodal discourse analysis theory emphasizes the use of pictures, audios, and videos, etc., to enable students to more deeply understand what they have learned. It can also improve the student's learning efficiency through the use of their sense organs. The application of multimodal discourse analysis theory in the College English teaching can obviously arouse the student's learning interest and enhance the teaching efficiency in the class.

\section{To Push the Multicultural Integration and Multimodal Development}

In the era of globalization, the people all over the world have more intense desire to communicate with each other. The single form of communication through language is far from meeting people's needs for interaction. So in this case, the multimode comes into being that combines pictures, audios, videos, and body language, etc. The teaching method of multimodal discourse analysis emerges due to the integration of the cultures in the world, which eliminates the barrier between different cultures. Therefore it is necessary to apply this teaching method into the College English teaching.

\section{To Perfect the College English Class and Improve the Teaching g Efficiency}

Through this kind of teaching, the teaching is divided into different forms of modal discourse, including the written language, images, videos, music, etc. The application of multimodal discourse can improve the teaching efficiency to great extent and strengthen the student's attention. At the same time, the diverse teaching tools can 
improve the student's leaning interest, avoiding the boredness brought about by the traditional teaching. The Internet proves to be beneficial for the students to broaden their horizon because of its extensive knowledge included. In addition, the situation simulation can provide the students with a real learning environment. They can experience the real learning situation, which undoubtedly will improve their learning interest. It put s the new drive into the College English teaching

\section{To Cultivate the Student's Multicultural Awareness and Develop the Learning Ability for Different Knowledge}

The traditional teaching mode has been out of date because of the globalization and the application of new techniques. Therefore the teaching reform in universities and colleges must be adopted accordingly. In College English teaching, importance not only should be attached to the students' English reading and writing skills, but also to develop the students' learning ability so that the student can have multicultural awareness (Fan, 2012). So it is beneficial for students to experience the real teaching situation through the application of multimodal teaching method to nurture their independent values. In the long run it also can improve their ability to adapt themselves to the society after graduation.

\section{The Approach to the Application of Multimodal Discourse in the College English Teaching}

Based on the multimodal discourse analysis theory, the trinity of the "teacher-student-assessment" is the important way to realize the multimodal College English teaching.

\section{The Multimodal Teaching by Teachers}

The multimodal teaching refers to the full use of the multimode to access, receive, and convey the information during some teaching procedures. That's to say, the teachers lay out the specific teaching procedures through the multimode and its combinations, such as words, pictures, audios, videos, PPTs, and Internet, etc., while students receive and cognize the messages by means of sense organs. So this kind of teaching is more challenging and teachers need to renew the teaching concepts to guide the College English teaching. In order to achieve this kind of teaching, the teachers need (1) to choose the proper teaching method for each teaching procedure and the suitable teaching mode accordingly; (2) to design the teaching activities on the basis of student's character, such as the role playing, the drama performance and the debate, etc., to arouse their learning interest and develop the multimodal cognitive ability; (3) to take advantage of all the resources, especially the modern teaching media to simulate the real situation to enhance the teaching effect, such as the Internet, the videos and movie clips.

\section{The Multimodal Learning by Students}

The multimodal learning refers to the student's cognitive ability to observe, analyze, and express the information through the multimode. It can be classified into two kinds through the teacher's instructions and the student's self-leaning. (1) Students learn the multimodal discourse expressions in the classroom. The teacher leads the student to acquiring and accessing the multimodal information and capturing the nonverbal information brought by teachers and other students quickly (Zhang, 2013). The students' first priority is to understand various symbols the teacher presents in the class and recognize the relationship among these symbols and the whole significance between the modes such as images, characters colors, and motions, etc. Multimodal learning in the 
class also includes many teaching forms used by teachers which can help students experience the information expressions visually, audibly, etc., to develop their capacity to cope with the multimodal discourse information. (2) Students learn by themselves in the classroom or after class. It means that the students conduct the self-learning visually, audibly based on their own leaning level, learning methods and teaching requirement. First of all, the students make the learning plan by themselves and finish the tasks assigned by teachers or set by themselves on their own in the given time. Secondly, students should know the approach to accessing the resources and acquire the information through various ways to solve the learning problems during the process of self-learning (Gu, 2016). Lastly, students learn the language in the natural and relaxing environment, and take advantage of the techniques to assist in the meaning construction, to know the potential meanings of each symbol, and finally utilize the symbols to present the meanings they want to express.

\section{The Multimodal Teaching Evaluation}

The multimodal teaching evaluation aims to improve the teaching by means of the systematic measurement toward the teachers based on a certain teaching objectives and teaching standard. It is an important part of teaching process and also the basis for the effective and successful teaching. Multimodal College English teaching calls for the systematic and comprehensive teaching evaluation system to prove its value and push its development furtherly in the practice. (1) Multimodal College English teaching needs the multimodal teaching evaluation system. The assessment of the multimodal College English teaching can't be conducted only from the verbal language and the roles of various symbols in the classroom teaching must be taken into consideration, such as images, videos, audios, PPTs, and Internet. Sometimes the limited class time has a conflict with the diverse teahching modes and affects the teaching effects. Therefore in the multimodal teaching evaluation the usage of the multimode and its role in the College English teaching should considered. (2) The multimodal classroom teaching needs the teacher's self-evaluation. The multimodal classroom teaching advocates that the teacher analyzes the usage of multimode in the teaching through their own teaching videos and the student's feedbacks. The teacher can find and solve the problems in the way of self-evaluation to improve the teaching quality in the multimodal College English class.

\section{Conclusion}

The multimodal discourse analysis theory provides a new perspective for the College English teaching. The teaching mode based on the multimodal discourse analysis theory supplies the authentic situation and the assistant condition for the College English teaching, thus improving the teaching efficiency greatly. In this kind of class, many modes can't be abused and arbitrarily combined. The choice of mode must cater to the discourse situation accordingly and proportionally. Therefore when the teacher makes the PPTs and chooses the way of multimodal teaching, the use of multimode must be reasonable, depending on the real situation. 


\section{References}

Fan, X. M. (November, 2012). A study of College English teaching from the perspective of multimodal discourse theory. Journal of Dalian Nationalities University, 14(6), 645-647.

Gu, X. Y. (Jul. 2016). Study of multimodal interaction framework under the network environment in College English. Higher Education Forum, 7, 69-73.

Kress, G., \& Van Leeuwen, T. (1996). Reading images: The grammar of visual design. London: Routledge.

Zhang, K. (2013). The application of multimodal discourse analysis theory of College English teaching in New Media Age. Journal of MuDangJiang College of Education, 2, 100-101. 